\title{
SiC-FET methanol sensors for process control and leakage detection
}

Zhafira Darmastuti, P. Bhattacharyya, Mike Andersson, Jayita Kanungo, Sukumar Basu, Per-

Olov Käll, Lars Ojamäe and Anita Lloyd Spetz

\section{Linköping University Post Print}

\section{Tweet}

N.B.: When citing this work, cite the original article.

Original Publication:

Zhafira Darmastuti, P. Bhattacharyya, Mike Andersson, Jayita Kanungo, Sukumar Basu, PerOlov Käll, Lars Ojamäe and Anita Lloyd Spetz, SiC-FET methanol sensors for process control and leakage detection, 2013, Sensors and actuators. B, Chemical, (187), SI, 553-562. http://dx.doi.org/10.1016/j.snb.2013.04.019

Copyright: Elsevier http://www.elsevier.com/

Postprint available at: Linköping University Electronic Press http://urn.kb.se/resolve?urn=urn:nbn:se:liu:diva- 85636 


\title{
SiC-FET Methanol Sensors for Process Control and Leakage Detection
}

\author{
Z. Darmastuti ${ }^{{ }^{*}}$, P. Bhattacharyya ${ }^{b}$, M. Andersson ${ }^{a}$, J. Kanungo ${ }^{c}$, S. Basu ${ }^{c}$, P-O. Käll ${ }^{a}$,
} L. Ojamäe ${ }^{a}, A$. Lloyd Spetz ${ }^{a}$

${ }^{a}$ Dept. of Physics, Chemistry and Biology, Linköping University, Sweden

b Dept. of Electronics and Telecommunication Engineering, Bengal Engineering and Science University, India

c IC Design \& Fabrication Centre, Department of Electronics and Telecommunication Engineering, Jadavpur University, India

\section{Abstract}

Two types of SiC based Field Effect Transistor sensors, with Pt or Ir gate, were tested to detect methanol in the concentration range $0-1600 \mathrm{ppm}$ for both process control and leak detection applications. The methanol response was investigated both with and without oxygen, since the process control might be considered as oxygen free application, while the sensor is operated in air during leak detection. Pt sensors offered very fast response with appreciably high response magnitude at $200^{\circ} \mathrm{C}$, while Ir sensors showed both higher response and response time up to $300^{\circ} \mathrm{C}$, but this decreased considerably at $350^{\circ} \mathrm{C}$. Cross sensitivity effect in presence of oxygen, hydrogen, propene and water vapor was also investigated. The presence of oxygen improved the response of both sensors, which is favorable for the leak detection application. Hydrogen had a large influence on the methanol response of both sensors, propene had a negligible influence, while water vapor changed direction of the methanol response for the $\mathrm{Pt}$ sensor. The detection mechanism and different sensing behavior of Pt and Ir gate sensors were discussed in the light of model reaction mechanisms derived from hybrid densityfunctional theory quantum-chemical calculations.

Key words: SiC-FET sensor, methanol, quantum-chemical calculation, Pt, Ir, gas sensor. 


\section{Introduction}

The high industrial $\mathrm{CO}_{2}$ emissions are believed to be the principal driving force for climate change and different types of $\mathrm{CO}_{2}$ capture techniques are now being considered high priority projects in thermal power generation plants. However, the post processing of such captured $\mathrm{CO}_{2}$ remains a question of great concern. Development of the process of $\mathrm{CO}_{2}$ conversion to methanol or other rich organic compounds [1] gives a very promising option to re-use captured $\mathrm{CO}_{2}$ as described in Fig.1. This option is especially interesting because it offers the possibility to use methanol as an energy carrier for energy produced from unreliable and intermittent primary energy sources such as solar, wind, or tidal power plants [1]. With this option, the $\mathrm{H}_{2}$ (Fig. 1) can be generated from renewable energy sources and will thus close the energy cycle. Recent advancement in the catalysis area contributes to the higher methanol yield at lower energy consumption $[2],[3]$ and this increases the importance of this process.

However, methanol is toxic even at modest concentrations (down to $200 \mathrm{ppm}$ ) and large scale handling of the substance has environmental implications, similar to those applying to conventional liquid fuels. Methanol sensors that can work at different ranges of methanol concentrations will therefore be very useful both for process control and leak detection.

The most accurate methods to measure methanol in an industrial facility is by wet chemistry methods, where the gas is sampled, cooled, and flowed to an external 
measuring device in the lab. However, this measurement results sometimes do not really represent the characteristic inside the process unit and it takes time. In-situ measurement is always preferable for industrial system, with wet chemistry methods as a reference for the control purpose. Electrochemical cell provides an accurate measurements, however, due to the electrolyte limitation, it is usually not possible to operate the sensor above $50^{\circ} \mathrm{C}[4]$. Therefore, a bypass will be required for these sensors. This approach will increase the cost and decrease the overall accuracy. Metal oxide sensors [5] [6] are also common for alcohol detection, including methanol. It can tolerate high temperature for in-situ measurement. However, it is limited by the oxygen content and the humidity of the process line. They usually can only operate with $20 \%$ oxygen content, resulting in the need of a bypass with the injection of additional air. Infrared optical sensors are usually preferable. However, they are usually much more expensive than the chemical sensors.

$\mathrm{SiC}$ based Field Effect Transistor (SiC-FET) gas sensors have proven excellent long term stability at high temperature and in harsh environments [7][8]. The sensitivity and selectivity of SiC-FET sensors can be tailored toward a specific test gas e.g. by changing the operating temperature and sensing (gate) material [7]. Hydrogen-containing gases like methanol, will typically dissociate upon adsorption on the sensor surface and released hydrogen will form a layer of polarized $\mathrm{OH}$ groups on the (gate) insulator surface, which will change the conductivity of the channel between source and drain in the transistor device, which in turn causes a change of the voltage-current profile [7][8].. 
In our earlier study, J. Kanungo et al reported the characteristics of SiC-FET sensors where either porous Pt or Ir metal were used as gate material for the detection of gaseous methanol in high concentrations (0.3-5\%) [9]. We concluded that the Pt sensors (at the optimum temperature of $200^{\circ} \mathrm{C}$ ) have higher sensitivity than the Ir sensors (at the optimum temperature of $250^{\circ} \mathrm{C}$ ), and that hydrogen cause cross-sensitivity at their respective optimum operating temperature. The present study is a continuation of this work where the following novel aspects are addressed:

- The study covers low (0 - 200 ppm) and medium concentrations (200-1600 ppm) of methanol.

- Besides hydrogen and propene, a study of the influence of different oxygen concentrations in the carrier gas has been carried out, as well as the influence of humidity.

- A more comprehensive theoretical study on the decomposition and oxidation of methanol on the catalytic metal gate (Pt or Ir) has also been performed. The study consists of the computation of energies and structures of the intermediate structures, activation energies for each steps of the surface reactions, and a comparison of the reaction mechanisms with and without the presence of oxygen. 


\section{Material and Methods}

\subsection{Experimental}

The sensor structure is described in Fig. 2(b). The sensing layer of Pt or Ir with $20 \mathrm{~nm}$ thickness was deposited as the catalytic metal gate of the SiC transistor device by DC magnetron sputtering. In order to form three phase boundaries, the film deposition was performed at a pressure of 50 mTorr to create a porous film. The film outside the gate area was removed by lift-off technique. The SiC transistor device is a commercial device provided by SenSiC AB (www.sensic.se). It is fully processed except for the gate metal. The device has a lift off pattern for the gate material, which makes it very convenient to process tailor made sensor devices for a certain application. The SiC substrate is naturally doped by nitrogen and epilayers are grown with nitrogen for n-type SiC and boron for $\mathrm{p}$ type SiC. The Ohmic contacts to drain, source and the backside of the SiC substrate consist of $50 \mathrm{~nm} \mathrm{Ni}$ (annealed at $950^{\circ} \mathrm{C}$ for $5 \mathrm{~min}$ in Ar), $50 \mathrm{~nm}$ TaSix as adhesion layer, and $400 \mathrm{~nm}$ Pt as oxygen diffusion barrier for high temperature operation.

The sensor chips were mounted into 16 pin headers together with individual heaters and temperature sensors as shown in Fig 2(c). The headers acted as a port for electrical and data connections to and from the sensors.

The measurement set up is shown in Fig. 2(a). The gas testing rig consisted of several mass flow controllers operated by a gas mixing program. Different concentrations of methanol were injected to the sensor chamber by adjusting the flow of the methanol and the carrier gas. The methanol concentration was varied between 0-1600 ppm. The 
methanol source was in the form of gas, from two gas bottles with different concentrations of methanol: 200 ppm for low concentrations and 2000 ppm for medium concentrations, diluted in $\mathrm{N}_{2}$. The operating temperature was varied between $150^{\circ} \mathrm{C}$ to $350^{\circ} \mathrm{C}$. The experiment was performed with two different carrier gases: pure $\mathrm{N}_{2}$ or $20 \%$ $\mathrm{O}_{2}$ in $\mathrm{N}_{2}$ and for some experiments, $10 \% \mathrm{O}_{2}$ in $\mathrm{N}_{2}$. The response was collected from the sensor every $2 \mathrm{~s}$. The sensor response, response time, and recovery time were calculated in the same way as described in the previous study [9]. Response was defined as the difference between the sensor signal when the test gas was introduced and the baseline. Response time was measured as the time needed to achieve $90 \%$ of the full response. Recovery time was defined as when the sensor signal had relaxed back to $10 \%$ of the baseline. For Pt, as the sensing material, in total 6 sensor devices (on two sensor chips) were tested and for Ir three devices (on the same sensor chip).

Similar to the earlier study for higher concentrations of methanol [9], the cross sensitivity to hydrogen and propene was also studied for the lower concentrations of methanol investigated in this paper. Besides, changes in response characteristics of the sensors towards different oxygen concentrations in the carrier gas and the influence of humidity are also reported in the present work. The study of the influence of humidity was performed by passing the test gas through a water bottle and assuming that the resulting gas was saturated with water vapor at $20^{\circ} \mathrm{C}$, which give a water content of about $2 \%$. 


\subsection{Theoretical Calculations}

The theoretical study concerned the modeling of the surface reactions on the catalytic metal gate by quantum chemical calculations. The Gaussian03 program [10] with the B3LYP [11][12][13] hybrid density functional and the LanL2MB [11][12][13] basis set was employed for the calculations.

The catalytic metal gate surface was modeled using clusters of metal atoms. Different sizes and shapes of Pt and Ir clusters were investigated by geometry optimization calculations to find the energy-minimum structures. In general, increasing the size of the cluster resulted in more stable structures, but also higher computational costs. The stability was indicated by lower energy difference between the total energy of the cluster divided by the number of atoms in the cluster, and the energy of a single atom.

As a compromise between those two parameters, clusters consisting of 14 atoms were chosen for both Pt and Ir because they were adequately small, sufficiently stable, and provided a sufficient number of atoms at the surface to allow for the interaction with methanol and other adsorbates.

Two sets of surface reactions were investigated for both Pt and Ir: with and without oxygen. For oxygen at the sensor's operating temperature, dissociative adsorption on the metal surface is more favorable than molecular adsorption [14]. Therefore, these calculations were performed with oxygen dissociated into $\mathrm{O}$ atoms on the metal surface. 
In agreement with the previous studies [15][16][17], the modeling of the methanol decomposition in this study involved the reaction mechanisms below. The numbers in the parentheses are the sequential numbers for each intermediate structure in the reaction mechanism for which the energies are presented, also later given in Fig. 12 and 13. The optimized structures of each species during methanol decomposition on the Pt surface are shown in Fig. 3, and the same mechanism is applied to the Ir surface. In between the stable species (reactants, intermediates and products), transition states (TS) were localized to determine the activation energy for each reaction.

a. The core reaction steps for methanol decomposition without oxygen (see also Fig. 3(a) and Section 3.3)

$$
\begin{aligned}
& \mathrm{CH}_{3} \mathrm{OH}(\mathrm{g}) \rightarrow \mathrm{CH}_{3} \mathrm{OH}(\mathrm{ad})(2) \\
& \mathrm{CH}_{3} \mathrm{OH}(\mathrm{ad})(2) \rightarrow \mathrm{TS} 1(3) \rightarrow\left\{\mathrm{CH}_{2} \mathrm{OH}(\mathrm{ad})+\mathrm{H}(\mathrm{ad})\right\}(4) \\
& (4) \rightarrow \mathrm{TS} 2(5) \rightarrow\{\mathrm{CHOH}(\mathrm{ad})+2 \mathrm{H}(\mathrm{ad})\}(6) \\
& (6) \rightarrow \mathrm{TS} 3(7) \rightarrow\{\mathrm{COH}(\mathrm{ad})+3 \mathrm{H}(\mathrm{ad})\}(8) \\
& (8) \rightarrow \mathrm{TS} 4(9) \rightarrow\{\mathrm{CO}(\mathrm{ad})+4 \mathrm{H}(\mathrm{ad})\}(10) \\
& (10) \rightarrow \mathrm{CO}(\mathrm{g})+4 \mathrm{H}(\mathrm{ad})(11) \\
& 2 \times\{\mathrm{H}(\mathrm{ad})+\mathrm{H}(\mathrm{ad})\} \rightarrow \mathrm{TS} 5(12) \rightarrow 2 \mathrm{H}_{2}(\mathrm{ad})(13) \\
& \mathrm{H}_{2}(\mathrm{ad}) \rightarrow \mathrm{H}_{2}(\mathrm{~g})
\end{aligned}
$$


Structure (1) (the reactants) is represented by the bare metal cluster and free methanol, i.e. $\mathrm{M} \_14+\mathrm{CH}_{3} \mathrm{OH}(\mathrm{g})$ and structure (14) (the products) is $\mathrm{M} \_14+\mathrm{CO}(\mathrm{g})+$ $2 \mathrm{H}_{2}(\mathrm{~g}) . \mathrm{M}$ is either Pt or Ir.

$b$. The core reaction steps for methanol oxidation with oxygen present (see also Fig. 3(b) and Section 3.3)

$$
\begin{aligned}
& \mathrm{M} \_14(1)+\mathrm{O}_{2}(\mathrm{~g}) \rightarrow 2 \mathrm{O}(\mathrm{ad})(2) \\
& \mathrm{CH}_{3} \mathrm{OH}(\mathrm{g})+2 \mathrm{O}(\mathrm{ad}) \rightarrow\left\{\mathrm{CH}_{3} \mathrm{OH}(\mathrm{ad})+2 \mathrm{O}(\mathrm{ad})\right\}(3) \\
& \left\{\mathrm{CH}_{3} \mathrm{OH}(\mathrm{ad})+2 \mathrm{O}(\mathrm{ad})\right\}(3) \rightarrow \mathrm{TS} 1(4) \rightarrow\left\{\mathrm{CH}_{2} \mathrm{OH}(\mathrm{ad})+\mathrm{OH}(\mathrm{ad})+\mathrm{O}(\mathrm{ad})\right\}(5) \\
& (5) \rightarrow \text { Multiple steps } \rightarrow\{\mathrm{O}-\mathrm{CO}(\mathrm{ad})+3 \mathrm{H}(\mathrm{ad})+\mathrm{OH}(\mathrm{ad})\}(7) \\
& (7) \rightarrow \mathrm{TS} 2(8) \rightarrow\left\{\mathrm{CO}_{2}(\mathrm{ad})+3 \mathrm{H}(\mathrm{ad})+\mathrm{OH}(\mathrm{ad})\right\}(9) \\
& (9) \rightarrow\{3 \mathrm{H}(\mathrm{ad})+\mathrm{OH}(\mathrm{ad})\}(10)+\mathrm{CO}_{2}(\mathrm{~g}) \\
& \{2 \mathrm{H}(\mathrm{ad})+\mathrm{OH}(\mathrm{ad})+\mathrm{H}(\mathrm{ad})\}(10) \rightarrow \mathrm{TS} 3(11) \rightarrow\left\{2 \mathrm{H}(\mathrm{ad})+\mathrm{H}_{2} \mathrm{O}(\mathrm{ad})\right\}(12) \\
& (12) \rightarrow 2 \mathrm{H}(\mathrm{ad})(13)+\mathrm{H}_{2} \mathrm{O}(\mathrm{g})
\end{aligned}
$$

Also the remaining two $\mathrm{H}$ atoms will react with oxygen to form $\mathrm{OH}$ groups and water and will be released from the surface.

The energies for the structures participating in the reactions on the Pt and Ir surfaces were compared to study the different characteristics of the sensing layers. For the reaction with oxygen present there were multiple reaction steps that were not explicitly investigated, in order to focus on the processes of adsorption and desorption (see 
Section 3.3). However, these reactions may by different for Pt and Ir, which deserves further studies in the future.

\section{Results and Discussion}

\subsection{Sensor characterizations}

The first sets of measurements were performed at a low concentration of methanol (0$200 \mathrm{ppm}$ ) with $\mathrm{N}_{2}$ as carrier gas. These tests were intended to test the sensor for process control applications. As shown in Fig. 4, the maximum response was achieved at $350^{\circ} \mathrm{C}$ for Pt sensors (a) and at $200^{\circ} \mathrm{C}$ for Ir sensors (b). It was also observed that for methanol concentrations lower than $20 \mathrm{ppm}$, both type of sensors could only detect if there was methanol present or not. The response starts to be proportional to the methanol concentration at around $50 \mathrm{ppm}$. In this case, the sensors can be utilized as a process control instrument down to a methanol concentration of $50 \mathrm{ppm}$.

For sensors like SiC-FET, which detect the electric field induced by the adsorbed species on the sensor surface, there is normally a maximum operation temperature for a certain gas response, which was demonstrated for $\mathrm{NH}_{3}$ and $\mathrm{CO}$ detection (in $10 \%$ oxygen/nitrogen atmosphere) [18][19]. This is because adsorption of gases increases at lower temperatures, while an increase in temperature normally speeds up chemical reactions and may even change reaction pathways. Temperature affects the kinetics of all chemical reactions. At low temperatures, the molecular species adsorb stronger, but it is harder to desorb them, and the overall reaction kinetics is slower. At higher 
temperatures, the chemical species adsorb less strong, but the reaction kinetics and the desorption rate are faster. This is implying that there is an optimum temperature at which the overall reactions proceeds most efficiently in order to get optimum sensing behavior of the gas sensor. Fig. 4(a) shows that the maximum response for Pt-gate sensors is at $250^{\circ} \mathrm{C}$, and then the response decreases at $300^{\circ} \mathrm{C}$. However, it increases again at $350^{\circ} \mathrm{C}$. The results suggest that at high temperature, the adsorbed species on the sensor surface might overcome the energy barrier for additional reactions to occur. There is possibly other species formed, which are detected by the sensors.

In the case of the Ir-gate sensors, it can be observed in Fig. 4(b) that the highest response is achieved at $200^{\circ} \mathrm{C}$. However, the response at $300^{\circ} \mathrm{C}$ and $350^{\circ} \mathrm{C}$ is higher than the response at $250^{\circ} \mathrm{C}$. Thus, also on the Ir sensor surface, the chemical reactions seem to give rise to different species, which are detected at different temperatures.

Furthermore, when comparing the transient signals as shown in Fig. 5, the preferable operating temperature is actually $200^{\circ} \mathrm{C}$ for Pt at the low methanol concentration. With response and recovery times of the order of 50-100s and 300-700s, respectively, the Pt sensors are very slow and unstable at $350^{\circ} \mathrm{C}$ when compared to the transient responses at $200^{\circ} \mathrm{C}$, which are fast and stable. This also indicates a different chemistry on the sensor surface at $200^{\circ} \mathrm{C}$ and $350^{\circ} \mathrm{C}$. 
In Fig. 4 the response level of Pt is higher than that for Ir. However, Fig. 6 reveals a reverse order at methanol concentration of $300-1600 \mathrm{ppm}$. In the later concentration range the Ir sensors show higher response and sensitivity (the derivative of the response versus the methanol concentration). In these measurements, the dynamic range of the Ir sensors in Fig. 6 is 50-1600 ppm, while for the Pt sensors it is only 50 to about 200 ppm.

As shown in Fig. 7 for 400 ppm methanol, the operating temperature that gives both the fastest response and recovery time is $350^{\circ} \mathrm{C}$ for both $\mathrm{Pt}$ and $\mathrm{Ir}$, and this is valid in the methanol concentration range $0-1600 \mathrm{ppm}$. It can be observed that the response time for the Ir sensors in the operating temperature range $150-300^{\circ} \mathrm{C}$ is on the average more than 10 times higher compared to that for the Pt sensors. For both leak detection and process control applications, sensors with shorter response time are more favorable. Since a lower operation temperature may also be favorable for long term stability operation, although Pt sensors exhibit lower response level for the methanol concentration of 300-1600 ppm, they may still be preferred over Ir sensors in some applications.

\subsection{Influence of other gases on the sensor response}

\subsubsection{Oxygen}

The influence of oxygen is especially important to study for the sensors intended for leak detection purposes. Therefore we have focused this study on low methanol 
concentrations (0-200 ppm). Based on our experiences, there is no significant difference of the sensor signal for oxygen concentrations between $10 \%$ and $20 \%$ in the carrier gas. For both cases of Pt and Ir sensors, the presence of oxygen in the carrier gas improves the performance by increasing the sensitivity as shown in Fig. 8. Moreover, the presence of oxygen also reduces the response and recovery time by about $50 \%$ as compared to pure nitrogen as the carrier gas. Methanol dissociates and is oxidized on top of the metal surface [15]. The oxygen decomposes on the metal surface and is involved in the interaction between the sensor surface and the methanol molecule [16], see section 2.2, reaction b. Improved response and recovery times in oxygen is normal for these type of sensors. However, the results in section 3.1 shows that applications of the methanol sensors, even in the oxygen free environment, also seems to be a possibility.

Fig. 9 shows the responses at methanol concentration of $20,400,800,1600$, and 50000 ppm in $10 \%$ or $20 \%$ oxygen, which reveals a shift in the temperature for optimum response. The results for $50000(5 \%)$ of methanol are taken from reference [9]. In the presence of oxygen for Pt-gate sensors in Fig. 9 a, there is a tendency that the higher the concentration of methanol, the lower the temperature for the maximum response. These phenomena also occur in the case of $\mathrm{CO}$ [18] and $\mathrm{NH}_{3}$ [19] detection with Pt-gate sensors. A comparison of Ir gate results in Fig.9 b indicates a more complicated chemistry on the Ir surface as compared to the Pt surface. 


\subsubsection{Hydrogen, propene, and humidity}

$\mathrm{CO}_{2}$ reduction into methanol via hydrogenation might yield several by-products such as small hydrocarbons, hydrogen, carbon monoxide, and water. Therefore studies on the cross sensitivity of hydrogen and propene, and also the influence of humidity, were performed.

For hydrogen and propene, the experiment was carried out with $80 \mathrm{ppm}$ of methanol in $\mathrm{N}_{2}$ at $200^{\circ} \mathrm{C}$ for the Ir sensor, see Fig. 10. In the first 3 pulses, 200 ppm hydrogen was introduced into the gas mixture followed by 3 pulses of $200 \mathrm{ppm}$ propene. The last 3 pulses contained only 80 ppm methanol. As shown in Fig. 10, 200 ppm hydrogen in the gas mixture gives around $80 \%$ increase of the response to methanol as compared to the original value for the Ir sensors. On the other hand, propene does not have much influence on the magnitude of the methanol response, which agrees with our previous study at a higher methanol concentration [9]. The same tendency is observed for Pt sensors at $200^{\circ} \mathrm{C}$, where $200 \mathrm{ppm}$ of hydrogen increases the response by about $30 \%$. Apparently, it is necessary to use additional sensors in the applications of the methanol sensor to compensate for the cross sensitivity caused by the presence of $\mathrm{H}_{2}$.

For the purpose of methanol purification in the process line, it is expected that the water vapor will be separated from methanol downstream of the reactor. However, there is still a possibility that the methanol reaching the sensor is not completely dry. This is likely also the case for leak detection applications, since the ambient air is never completely 
dry. Therefore, it is important to study how humidity affects the sensor signal. It should be noted that in this study, it was not possible to adjust the humidity level. The operating temperature is $300^{\circ} \mathrm{C}$ because below this temperature the results are shaky and difficult to evaluate. The reason for this may be unstable reaction species on the sensor surface but may also be poor electrical contact due to condensation of water, e.g on bonding wires which were not heated during these experiments. This should be clarified in future studies.

Fig. 11 shows the preliminary results for the influence of water vapor on the sensor response. For both the $\mathrm{Pt}$ and Ir sensors, the presence of water vapor changes the direction of the response, which also decreases by a factor of 20 . Smaller response might for example be due to a competition between the methanol and the water molecules for the available adsorption sites on the metal surface[20]. It is surprising that the influence of humidity in this study is much larger than in the previous studies for SiC FET devices [19], [20], [21], [22] for other gases. Different from hydrogen or ammonia, methanol might also react with water vapor and undergo partial oxidation or create complex molecules which give less response when adsorbed on the sensor surface. Further studies are therefore needed to fully understand the reason for this discrepancy.

However, the result for the Pt sensors is even more special because when humidity is present, the sensor response becomes smaller with higher concentration of methanol. The same phenomena, regarding the change of the response direction and the tendency 
of reduced response when the gas concentration increases, are also observed for some metal oxide sensors [23]. It might be related to changes in the formation and coverage of the $\mathrm{OH}$ groups on the sensor surface and consequently the electric field, which is reflected in the change of the source-drain current of the transistor. There is also the possibility of competing reactions taking place in the gas phase, resulting in the formation of complex molecular species which poison the sensor surface. One can speculate that different reactions become dominant when water vapor is present compared to the dry conditions.

Studies on how humidity can influence the sensor response are not only very interesting from a theoretical and scientific point of view but may also have important practical implications. To ensure that the sensors measure the methanol properly in a humid environment, it is also possible to consider the design of the sensor packaging. Since the test gas in both leakage detection and process control applications is clean, introduction of desiccant upstream the sensor in the packaging should make the data evaluation easier.

\subsection{Computational studies of surface reactions}

Two cases of methanol decomposition on the sensor surface were studied: with and without oxygen present. Without the presence of oxygen, methanol decomposes into CO and $\mathrm{H}_{2}$ [17]. While in the presence of oxygen methanol is oxidized to $\mathrm{CO}_{2}$ and $\mathrm{H}_{2} \mathrm{O}$. The 
reaction mechanisms for both cases are described in Section 2.2. The optimized structures of the reaction mechanism for the reactions both with and without oxygen are presented in Fig. 3.

The computational results for methanol decomposition without oxygen present are visualized in Fig. 12. Solid lines connect intermediate species and dashed lines connect intermediates to transition states (TS). The Ir surface has a higher adsorption energy for methanol (3,15 eV for Ir and 2,44 eV for Pt) and higher desorption energy for $\mathrm{H}_{2}$ (1,54 eV for Ir and $0,18 \mathrm{eV}$ for $\mathrm{Pt}$ ) than the Pt surface. The higher energies for adsorption and desorption influences the response and recovery time. These results agree with the experimental observations that Ir has slower response and recovery times below $350^{\circ} \mathrm{C}$. However, the activation energy for some of the reaction steps during methanol decomposition seems to be higher for the Pt surface.

In our study methanol decomposes as follows:

$$
\begin{aligned}
& \mathrm{CH}_{3} \mathrm{OH}(\mathrm{ad}) \rightarrow \mathrm{CH}_{2} \mathrm{OH}(\mathrm{ad})+\mathrm{H}(\mathrm{ad}) \rightarrow \mathrm{CHOH}(\mathrm{ad})+2 \mathrm{H}(\mathrm{ad}) \rightarrow \mathrm{COH}(\mathrm{ad})+3 \mathrm{H}(\mathrm{ad}) \\
& \rightarrow \mathrm{CO}(\mathrm{ad})+4 \mathrm{H}(\mathrm{ad})
\end{aligned}
$$


Table 1. Activation energies (in eV)

\begin{tabular}{|c|c|c|c|c|c|c|}
\hline Reaction steps & $\begin{array}{l}\mathrm{CH}_{3} \mathrm{OH}(\mathrm{ad}) \rightarrow \\
\mathrm{CH}_{2} \mathrm{OH}(\mathrm{ad})+ \\
\mathrm{H}(\mathrm{ad})\end{array}$ & $\begin{array}{l}\mathrm{CH}_{2} \mathrm{OH}(\mathrm{ad}) \\
\mathrm{H}(\mathrm{ad}) \\
\mathrm{CHOH}(\mathrm{ad}) \\
2 \mathrm{H}(\mathrm{ad})\end{array}$ & $\begin{array}{l}+ \\
+ \\
+\end{array}$ & $\begin{array}{l}\mathrm{CHOH}(\mathrm{ad}) \\
2 \mathrm{H}(\mathrm{ad}) \\
\mathrm{CHO}(\mathrm{ad}) \\
3 \mathrm{H}(\mathrm{ad})\end{array}$ & $\begin{array}{l}+ \\
\rightarrow \\
+\end{array}$ & $\begin{array}{l}\mathrm{COH}(\mathrm{ad})+ \\
3 \mathrm{H}(\mathrm{ad}) \\
\rightarrow \mathrm{CO}(\mathrm{ad})+4 \mathrm{H} \\
(\mathrm{ad})\end{array}$ \\
\hline $\begin{array}{l}\text { Activation } \\
\text { energy for } \mathrm{Pt}\end{array}$ & 2.14 & 0.53 & & 2.09 & & 0.42 \\
\hline $\begin{array}{l}\text { Activation } \\
\text { energy for Ir }\end{array}$ & 1.15 & 2.49 & & 1.66 & & 1.6 \\
\hline
\end{tabular}

The activation energies for the above reactions steps are shown in Table 1 . Both the adsorption/desorption energies as well as the activation energies for each reaction step will influence the sensor response. As depicted in Fig. 6 and Fig. 8, at certain operating condition and/or methanol concentration, the Pt sensor gives the higher response but when the parameters change, the Ir sensors might exhibit the higher response. In other words, the operating conditions and methanol concentrations will be critical in determining the rate-determining step for the response.

Fig. 13 shows the energies of the intermediate structures and transition states during the methanol oxidation on the sensor surface. As seen in Fig. 13, the Ir sensors have higher methanol adsorption energy (7,23 eV for Ir and 5,13 eV for $\mathrm{Pt})$, higher $\mathrm{CO}_{2}$ desorption energy $\left(2,16 \mathrm{eV}\right.$ for Ir and 1,94 eV for $\mathrm{Pt}$ ), higher $\mathrm{H}_{2} \mathrm{O}$ desorption energy (6 eV for Ir and 
2,24 eV for Pt), and higher activation energies. As the case without the presence of oxygen, high adsorption and desorption energies lead to slower response and recovery times of the Ir sensors compared to those of the Pt sensors, but also larger response.

Fig. 13 shows that the energy needed to desorb water is less for Pt than for Ir. When the effect of blocking of adsorption sites is negligible, Ir and Pt sensors behave differently in the presence of water vapor. For hydrogen exposure in Ref. [24], the Ir sensors give higher response when the humidity increases while the Pt sensors give smaller response. Yamaguchi et al [25] also mentioned that the dominant mechanism in hydrogen sensing is due to the water formation on the sensor surface, and this is likely to have a large influence on hydrogen-containing species like methanol. References [24] and [25] relate to SGFETs such that the response reactions take place on the gate contact layer while for the SiC- FETs the response emanates from the gate insulator surface. The comparison is still very interesting but may not be totally relevant. In the case here, the difference in desorption energy might be one of the causes for the different sensing behavior of Ir and Pt when water vapor is produced.

Fig. 12 and Fig. 13 show that the adsorption energy for the system without oxygen is lower for both Pt and Ir which might explain the smaller sensor response. The other point to be noted here is that in the end of the reaction the relative energy of the end products is smaller in the case where oxygen is present, which might explain the faster recovery time. 
As mentioned in Section 3.2.2 when discussing the influence of humidity, it is also important to perform computational studies on how the water vapor influences on the interaction between the catalytic metal and the test gas. In future work, there are several possibilities that might be considered. Water might for example be co-adsorbed on the sensor surface with methanol, or it might form a water network on the surface, or it might also be partly ionized due to the presence of the electrical field on the sensing devices. The computed reaction profiles can help to decide which scenario is most likely to occur.

\section{Future Outlook}

The observation that humidity influences the characteristics of Pt-gate and Ir-gate SiCFET sensor responses raises many fundamental questions that cannot yet be answered in the present report. It would be very interesting to find out what actually occurs on the sensor surface, since that may cause the anomalies in the sensing behavior. Our next work will therefore be an investigation of the surface reactions by analyzing the residual gas by mass spectrometry. Furthermore, the adsorbates on the sensor surface will be studied by DRIFT, diffuse reflectance infrared Fourier transform, spectroscopy. The combined information, eventually together with theoretical modeling, may give suggestions of the surface reactions and possibly identify some of the intermediate products. It is important to do more theoretical calculation on the surface reactions in addition to the experimental work, for example in the presence of water molecules. 
These calculations might help to explain the influence of water vapor to the particular behavior of the sensors, especially the inverted signal.

As previously stated, it is necessary to have additional hydrogen and humidity sensors on the process line to overcome the selectivity challenge. These sensors are actually needed for the process control as well. Besides the possibility to run sensor arrays, it is also possible to improve the sensitivity of the sensors with temperature cycling operation [26]. This method has shown promising results for detecting the target gases, even in a background of changing gas mixture. Further work with the combination of sensor arrays and temperature cycling operation will likely be an advantage over the existing solutions, with large potential for powerful sensor systems both for process control and methanol leak detection.

\section{Conclusions}

SiC-FET sensors with Pt gate at $200^{\circ} \mathrm{C}$ are superior to sensors with Ir gate as methanol sensors for process control applications especially because of the fast response time (less than 20s) in the concentration regime (0-1600ppm) as well as the consideration that low temperature operation (below $300^{\circ} \mathrm{C}$ ) is favorable for long term stability concern of the sensor. Among other interfering gases, which might co-exist in the mixture, oxygen improved the performance by increasing the size of the response around $20 \%$ and reducing the recovery time by $50 \%$, hydrogen showed cross-sensitivity by up to $80 \%$ 
increase of the response, while propene did not influence the methanol sensing. An interesting phenomenon was observed when water vapor was added to the gas mixture. There was a change in the direction of response for both the Pt and Ir gate FET sensors. In addition to that, in case of the Pt gate sensors the response magnitude decreased with increasing gas concentrations. Overall, Ir-gate sensors are better for the methanol concentration between 0-1600 ppm, especially when humidity is present. Different sensing behavior of Pt and Ir was studied by quantum-chemical computations of the energy profiles for the reactions on the metal surface. Without oxygen, the Ir surface has

a higher adsorption energy for methanol (3,15 eV for $\mathrm{Ir}$ and 2,44 eV for $\mathrm{Pt}$ ) and desorption energy for $\mathrm{H}_{2}(1,54 \mathrm{eV}$ for Ir and $0,18 \mathrm{eV}$ for Pt) than the Pt surface. In the presence of oxygen, Ir sensors have higher methanol adsorption energy $(7,23 \mathrm{eV}$ for Ir and 5,13 eV for $\mathrm{Pt})$, higher $\mathrm{CO}_{2}$ desorption energy $(2,16 \mathrm{eV}$ for $\mathrm{Ir}$ and 1,94 eV for $\mathrm{Pt})$, higher $\mathrm{H}_{2} \mathrm{O}$ desorption energy ( $6 \mathrm{eV}$ for $\mathrm{Ir}$ and 2,24 eV for Pt), and higher activation energies.

\section{Acknowledgements}

The authors acknowledge the Swedish Research Council for grants, NSC for the computing resources and Sensic $A B$ for supplying sensors and other resources. Last but not least Peter Möller is acknowledged for all the help in setting up the laboratory equipment. 


\section{References}

[1] G.A. Olah, After Oil and Gas: Methanol Economy, Catal. Lett. 93 (2004) 1-2.

[2] Y. Yang, J. Evans, J. A. Rodriguez, M. G. White and P. Liu, Fundamental studies of methanol synthesis from $\mathrm{CO}_{2}$ hydrogenation on $\mathrm{Cu}(111), \mathrm{Cu}$ clusters, and Cu/ZnO(001), Phys. Chem. Chem. Phys. 12 (2010) 9909-9917.

[3] X. Liu, G. Q. Lu, Z. Yan, and J. Beltramini, Recent Advances in Catalysts for Methanol Synthesis via Hydrogenation of CO and CO, Ind. Eng. Chem. Res., 42 (25), (2003) $6518-6530$.

[4] Detcon Model DM-100-CH3OH methanol sensor. Detcon Inc. www.detcon.com

[5] S. Wei, M. Zhou, and W. Du, Methanol Sensing Properties of Electrospun $\mathrm{SnO}_{2}-\mathrm{ZnO}$ Nanofibers, Advanced Materials Research, 2012, Vol. 356-360.

[6] TGS 822 Figaro alcohol sensor, Figaro USA Inc., www.figarosensor.com

[7] M. Andersson, P. Ljung, M. Mattsson, M. Lofdahl and A. Lloyd Spetz, Investigations on the possibilities of a MISiCFET sensor system for OBD and combustion control utilizing different catalytic gate materials, Topics in Catalysis 30/31 (2004) 365-368.

[8] I. Lundström, H. Sundgren, F. Winquist, M. Eriksson, C. Krantz-Rülcker, A. Lloyd Spetz, Twenty-five years of field effect gas sensor research in Linköping, Sensors and Actuators B, 121 (2007) 247-262.

[9] J. Kanungo, M. Anderson, Z. Darmastuti, S. Basu, P.O. Kall, L. Ojamae, and A.L. Spetz, Development of SiC-FET methanol sensor, Sensors and Actuators B-Chemical (2011) pp. 72-78. 
[10] M.J. Frisch, G.W. Trucks, H.B. Schlegel, G.E. Scuseria, M.A. Robb, J.R. Cheeseman, J. Montgomery, J. A., T. Vreven, K.N. Kudin, J.C. Burant, J.M. Millam, S.S. Iyengar, J. Tomasi, V. Barone, B. Mennucci, M. Cossi, G. Scalmani, N. Rega, G.A. Petersson, H. Nakatsuji, M. Hada, M. Ehara, K. Toyota, R. Fukuda, J. Hasegawa, M. Ishida, T. Nakajima, Y. Honda, O. Kitao, H. Nakai, M. Klene, X. Li, J.E. Knox, H.P. Hratchian, J.B. Cross, V. Bakken, C. Adamo, J. Jaramillo, R. Gomperts, R.E. Stratmann, O. Yazyev, A.J. Austin, R. Cammi, C. Pomelli, J.W. Ochterski, P.Y. Ayala, K. Morokuma, G.A. Voth, P. Salvador, J.J. Dannenberg, V.G. Zakrzewski, S. Dapprich, A.D. Daniels, M.C. Strain, O. Farkas, D.K. Malick, A.D. Rabuck, K. Raghavachari, J.B. Foresman, J.V. Ortiz, Q. Cui, A.G. Baboul, S. Clifford, J. Cioslowski, B.B. Stefanov, G. Liu, A. Liashenko, P. Piskorz, I. Komaromi, R.L. Martin, D.J. Fox, T. Keith, M.A. Al-Laham, C.Y. Peng, A. Nanayakkara, M. Challacombe, P.M.W. Gill, B. Johnson, W. Chen, M.W. Wong, C. Gonzalez, and J.A. Pople, Gaussian 03, Revision C.02, Gaussian, Inc., Wallingford CT (2004).

[11] A. D. Becke, Density-functional exchange-energy approximation with correct asymptotic-behavior, Phys. Rev. A, 38 (1988) 3098-3100.

[12] C. Lee, W. Yang, and R. G. Parr, Development of the Colle-Salvetti correlationenergy formula into a functional of the electron density, Phys. Rev. B, 37 (1988) 785-89.

[13] P. J. Hay and W. R. Wadt, Ab initio effective core potentials for molecular calculations - potentials for the transition-metal atoms Sc to Hg, J. Chem. Phys., 82 (1985) 270-83. 
[14] I.A. Erikat, B.A. Hamad, J.M. Khalifeh, A density functional study on adsorption and dissociation of $\mathrm{O}_{2}$ on $\operatorname{Ir}(100)$ surface, Chemical Physics 385 (2011) 35-40.

[15] H. Amandusson, L.-G. Ekedahl, H. Dannetun, Methanol-induced hydrogen permeation through a palladium membrane, Surface Science 442 (1999) 199-205

[16] M. Eriksson, and L.G. Petersson, Spillover of hydrogen, oxygen, and carbon monoxide in oxidation reaction on SiO2 supported Pd, Surface Science (1994) pp. 139-152.

[17] B.A. Sexton, Methanol decomposition on platinum (111), Surface Science (1981) pp. 271-281.

[18] M. Andersson, H. Wingbrant, A. Lloyd Spetz, Study of the CO Response of SiC based Field Effect Gas Sensors, Proc. IEEE Sensors 2005, Irvine, USA, October 31November 2, 2005, pp. 105-108.

[19] H. Wingbrant, H. Svenningstorp, P. Salomonsson, D. Kubinski, J. H. Visser, M. Löfdahl, A. Lloyd Spetz, Using a MISiC-FET Sensor for Detecting $\mathrm{NH}_{3}$ in SCR Systems, IEEE Sensors Journal, Vol. 5, No. 5 (2005) pp. 1099-1105.

[20] C. F. Lo, C. Y. Chang, B. H. Chu, S. J. Pearton, A. Dabiran, P. P. Chow, and F. Ren, Effect of humidity on hydrogen sensitivity of Pt-gated AlGaN/GaN high electron mobility transistor based sensors, Applied Physics Letters 96 (2010) 232106.

[21] Lampe U, Simon E, Pohle R, Fleischer M, Meixner H, Frerichs H-, Lehmann M, Kiss G. GasFET for the detection of reducing gases. Sensors and Actuators, B: Chemical (2005);111-112(SUPPL.):106-10. 
[22] S. Nakagomi, P. Tobias, A. Baranzahi, I. Lundström, P. Mårtensson, and A. Lloyd Spetz, Influence of carbon monoxide, water, and oxygen on high temperature catlaytic metal - oxide - silicon carbide structures, Sensors and Actuators B, 45/3 (1997) 183-191.

[23] Ruth Pearce, Alexander Hagelin, Per-Olov Käll, Rositza Yakimona, Anita Lloyd Spetz, Elin Becker, Magnus Skoglundh, Effect of Water Vapour on Ga Doped ZnO Nanoparticle Sensor Gas Response, Proc. IEEE Sensors 2009, Christchurch, New Zealand, Oct 26-28 (2009) pp. 2039-2044

[24] K. Scharnagl, A. Karthigeyan, M. Burgmair, M. Zimmer, T. Doll, I. Eisele, Low temperature hydrogen detection at high concentrations: comparison of platinum and iridium, Sensors and Actuators B 80 (2001) 163-168.

[25] T. Yamaguchi, T. Kiwa, K. Tsukada, and K. Yokosawa, Oxygen interference mechanism of platinum-FET hydrogen gas sensor. Sensors and Actuators A: Physical (2007) pp. 244-248.

[26] C. Bur, P. Reimann, M. Andersson et al., "Increasing the Selectivity of Pt-Gate SiC Field Effect Gas Sensors by Dynamic Temperature Modulation" IEEE Sensors Journal, vol. 12, no. 6, Jun, 2012. 
Figure Captions

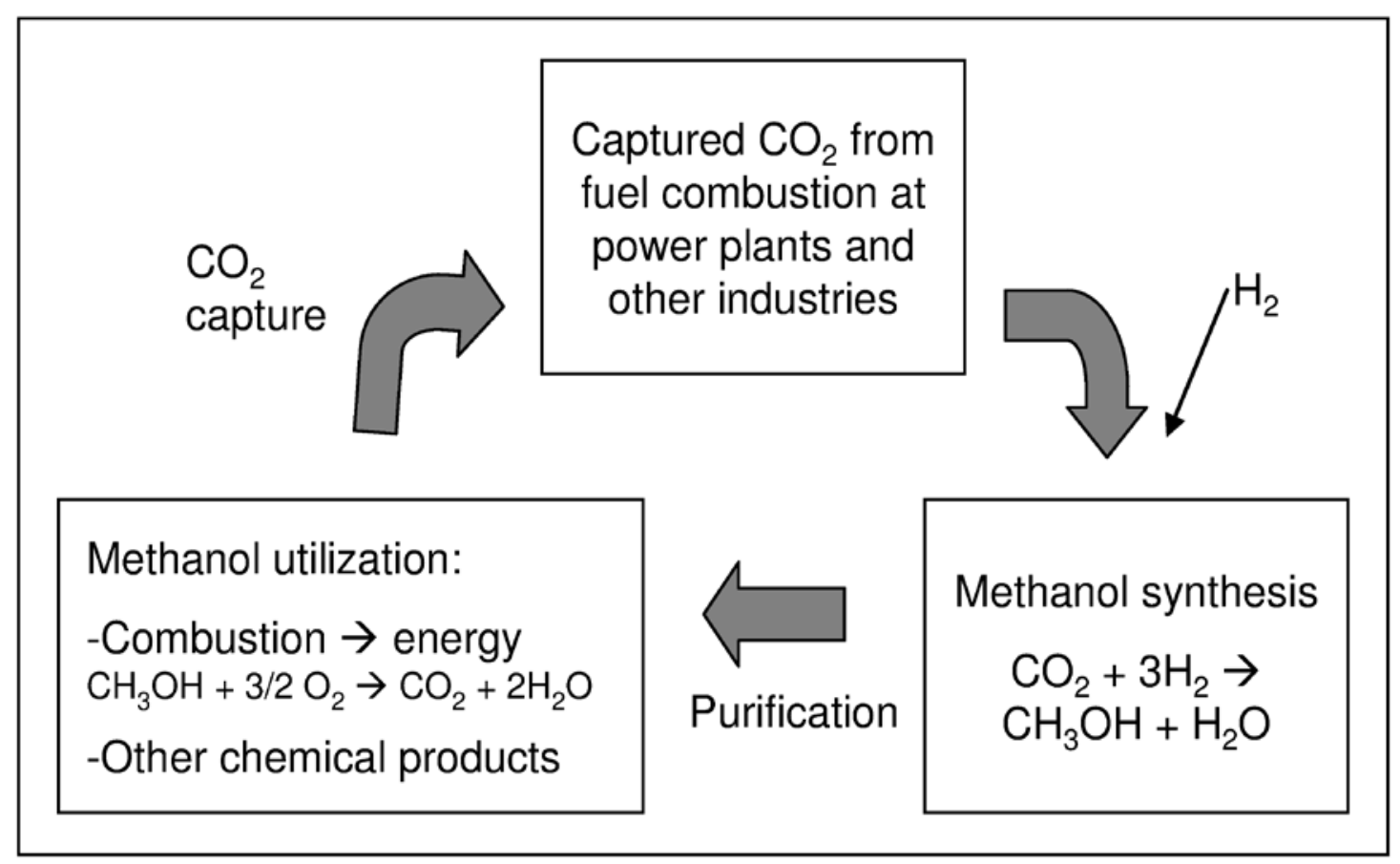

Figure 1 Methanol Cycle 

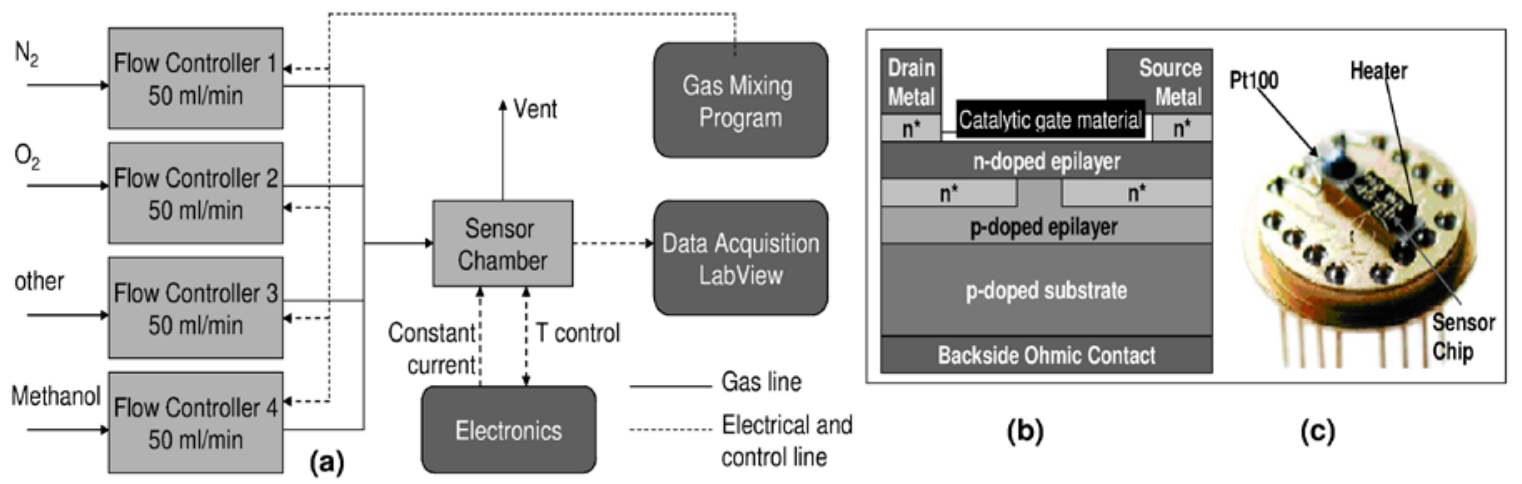


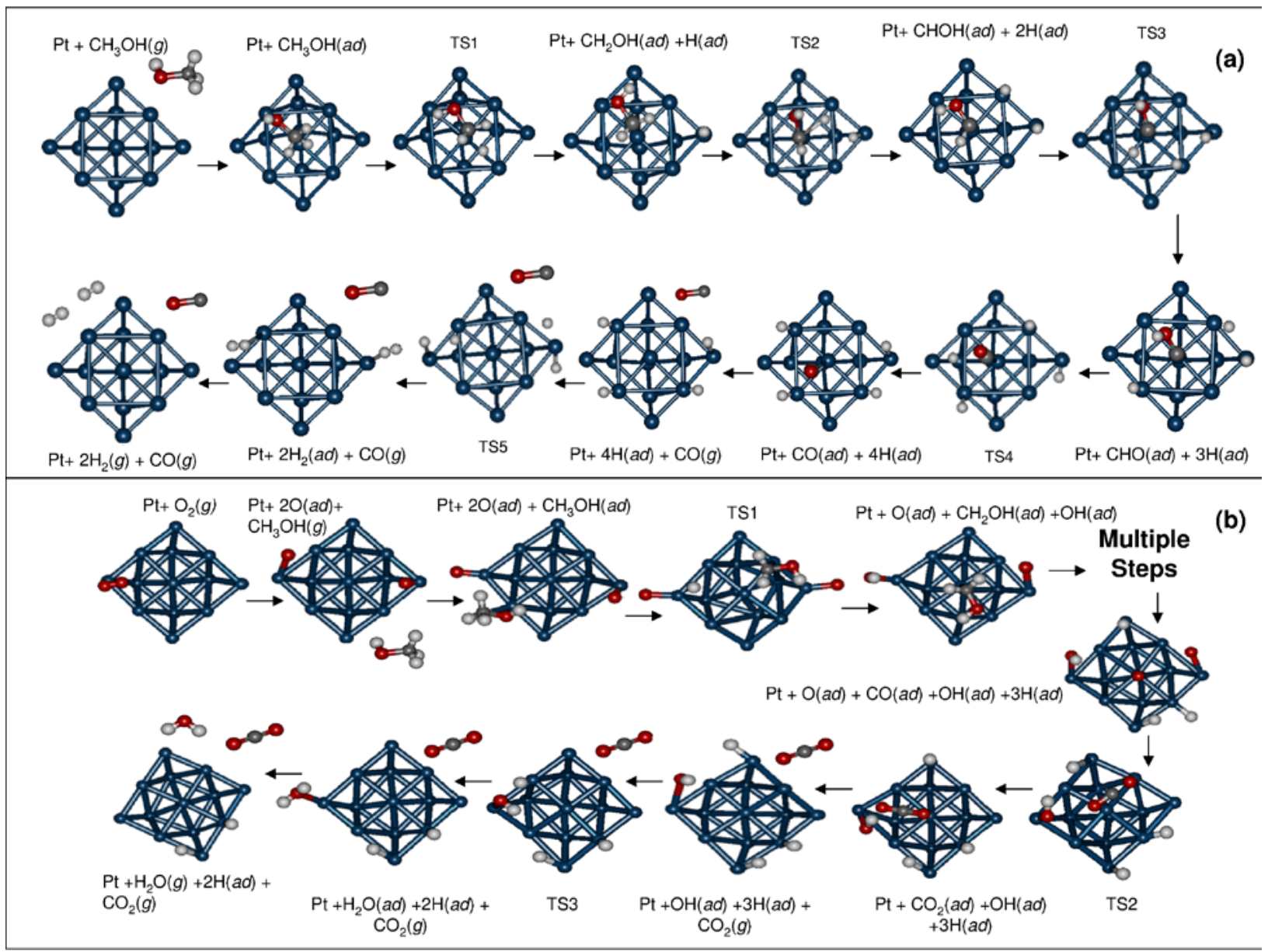

Figure 3 Optimized structures for methanol decomposition on Pt clusters

(a) without oxygen (b) with oxygen 

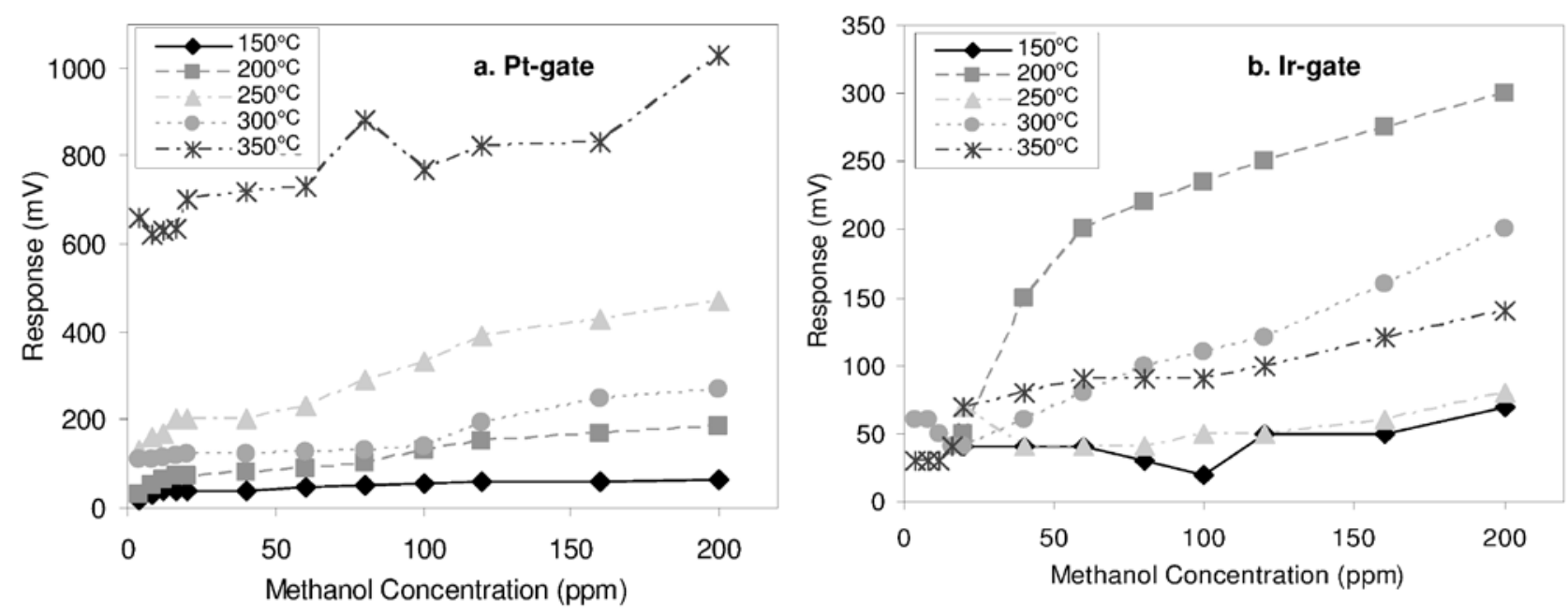


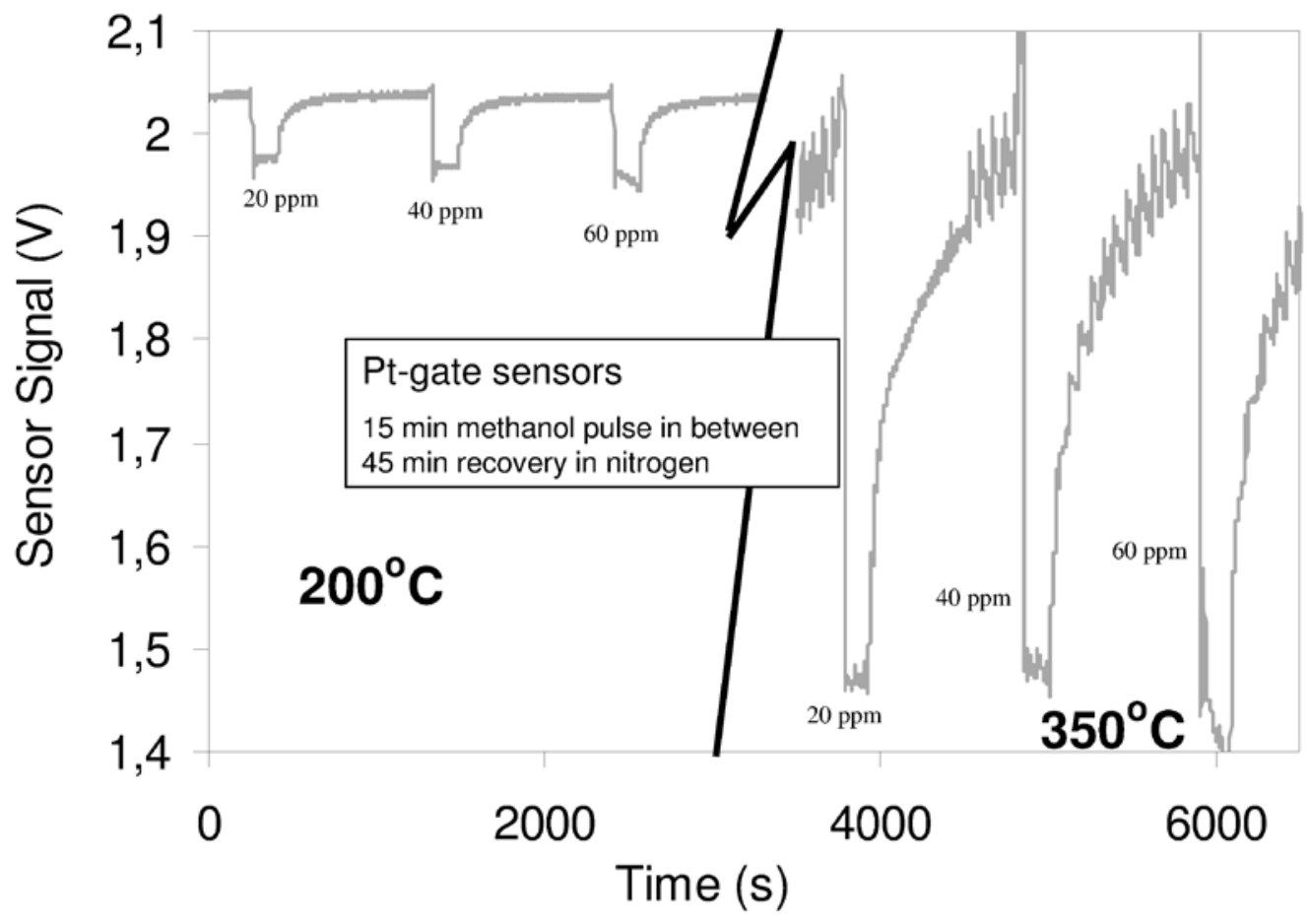

Figure 5 Comparison of the transient signal of Pt sensors at low methanol concentration at $200^{\circ} \mathrm{C}$ and $350^{\circ} \mathrm{C}$ 

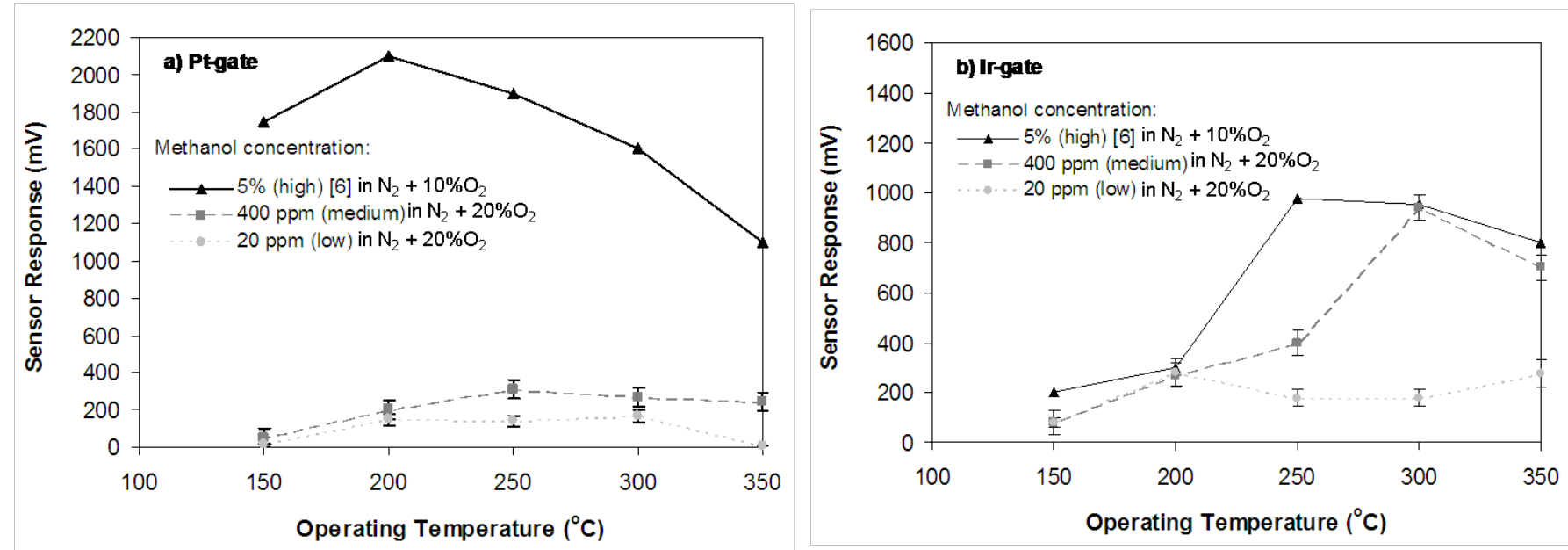

Figure 6 Response vs. methanol concentration in $\mathrm{N}_{2}$ at the optimum operating temperature 


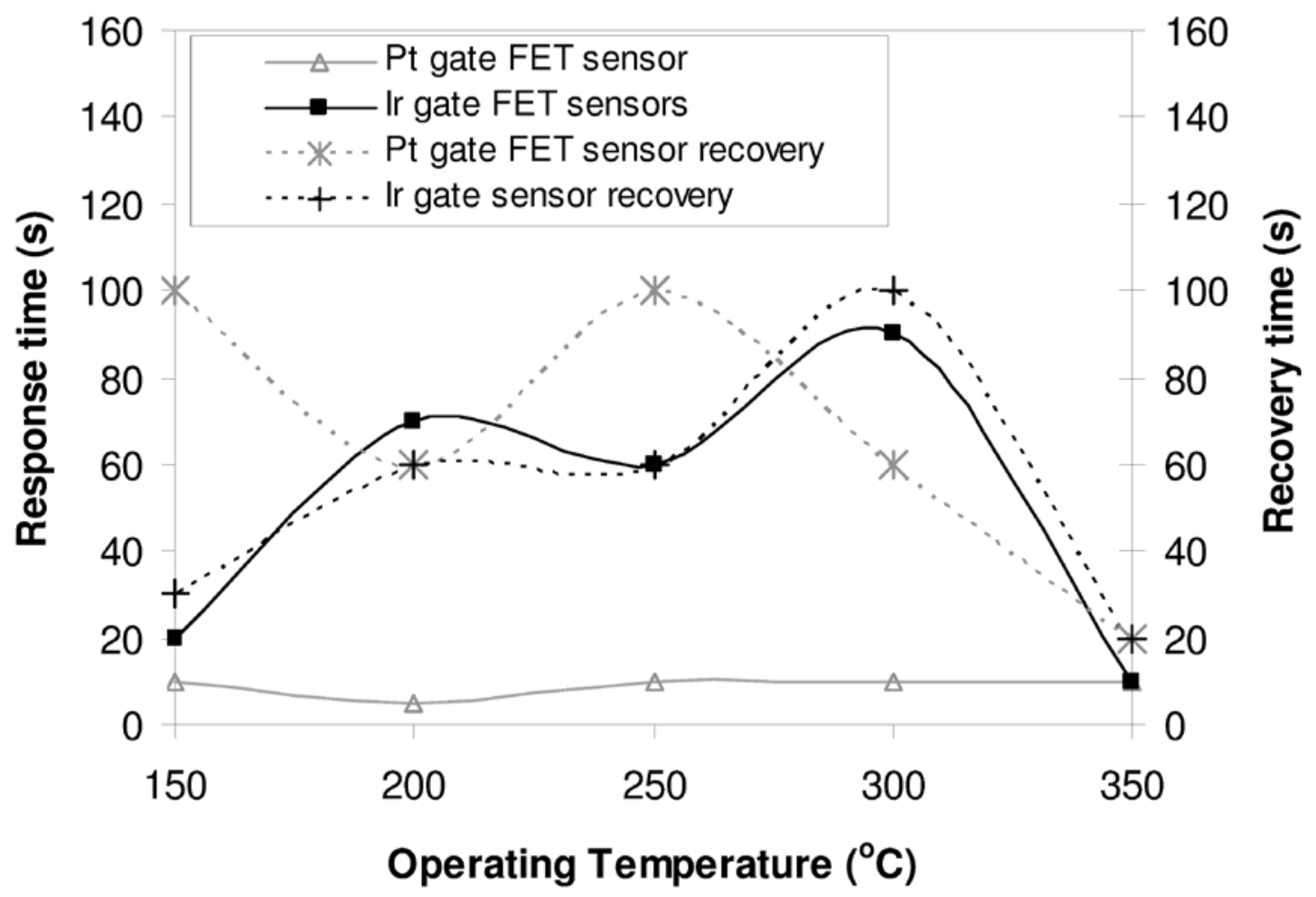

Figure 7 Response and Recovery Time profile of 400 ppm methanol in $\mathrm{N}_{2}$ at different operating temperatures 


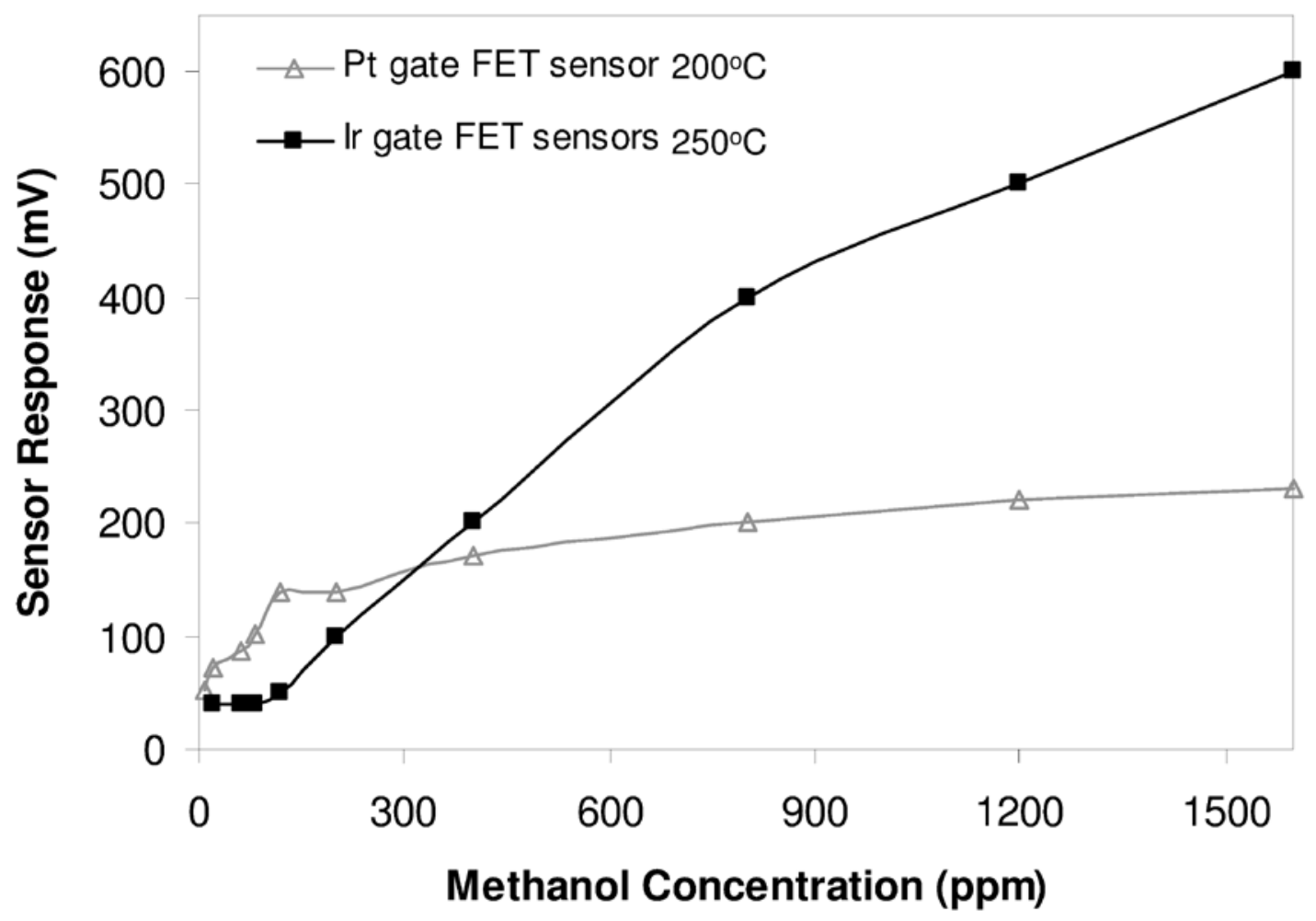

Figure 8 Influence of oxygen at the low concentration (0-200ppm) of methanol at $200^{\circ} \mathrm{C}$ 


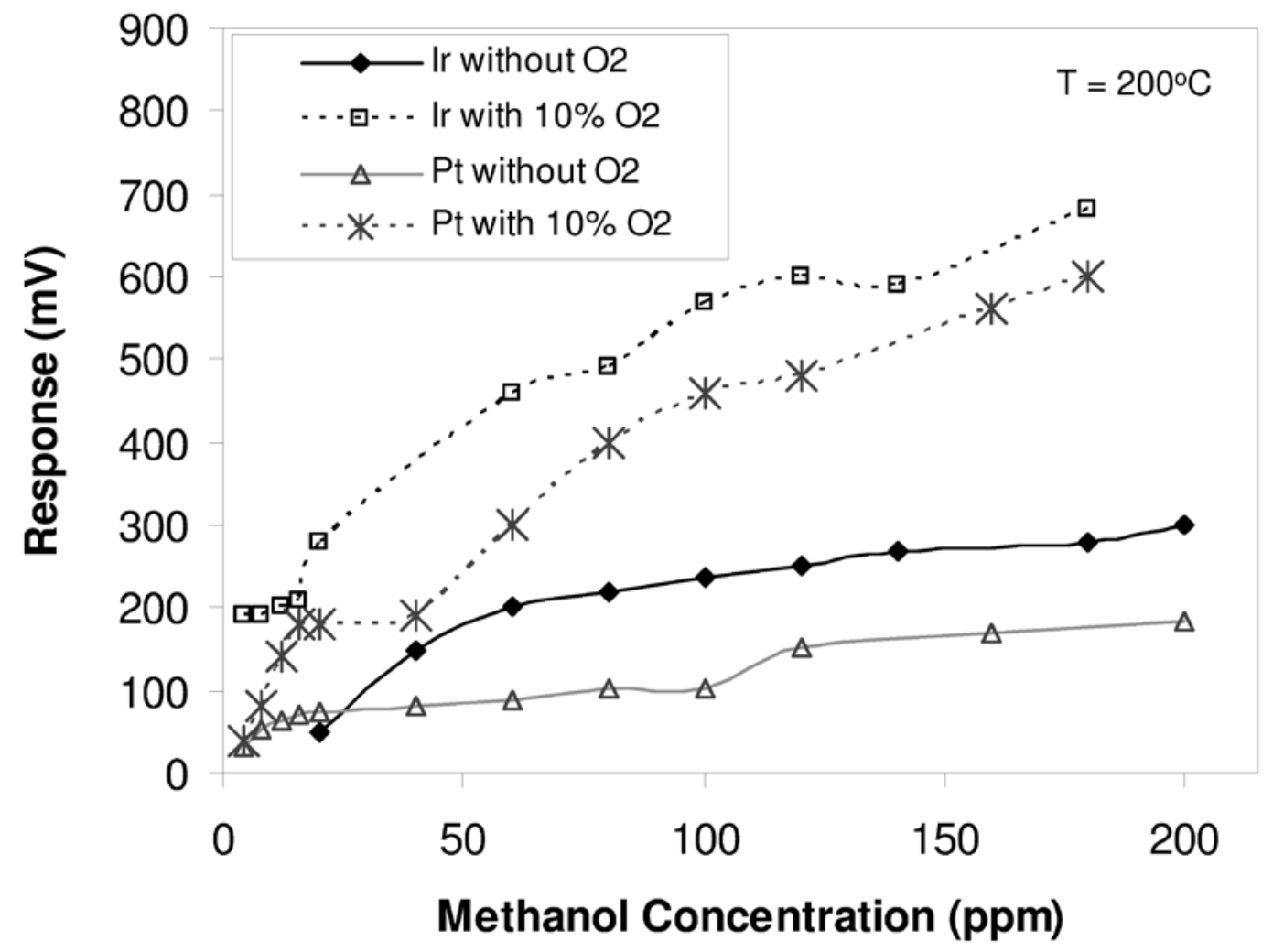

Figure 9 Response profile of (a) Pt-gate sensors and (b) Ir-gates sensors for the methanol concentrations of $20-1600$ ppm, and 50000 ppm at different operating temperatures 


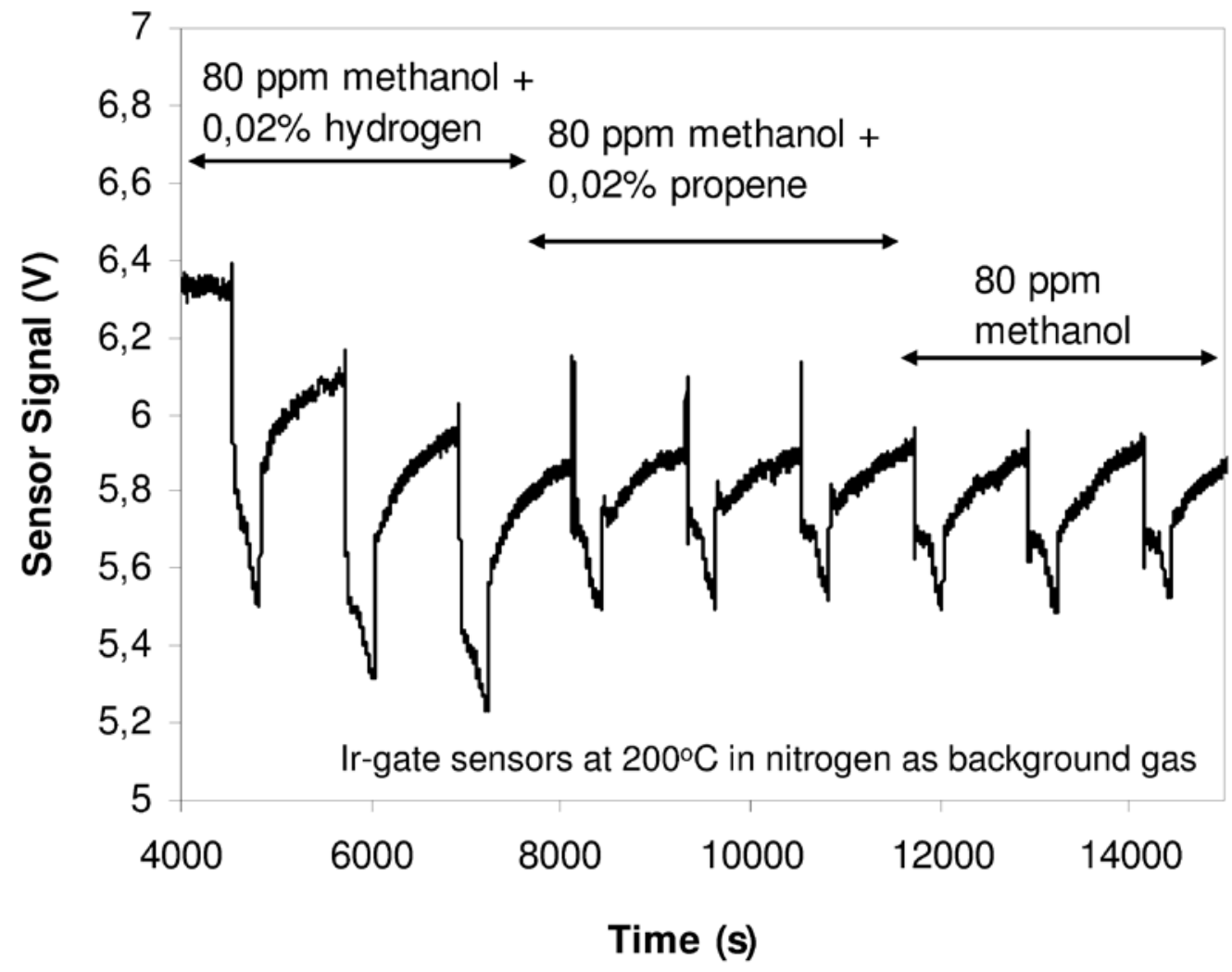

Figure 10 Cross-sensitivity for methanol to hydrogen and propene in nitrogen for Ir sensors at $200^{\circ} \mathrm{C}$ 


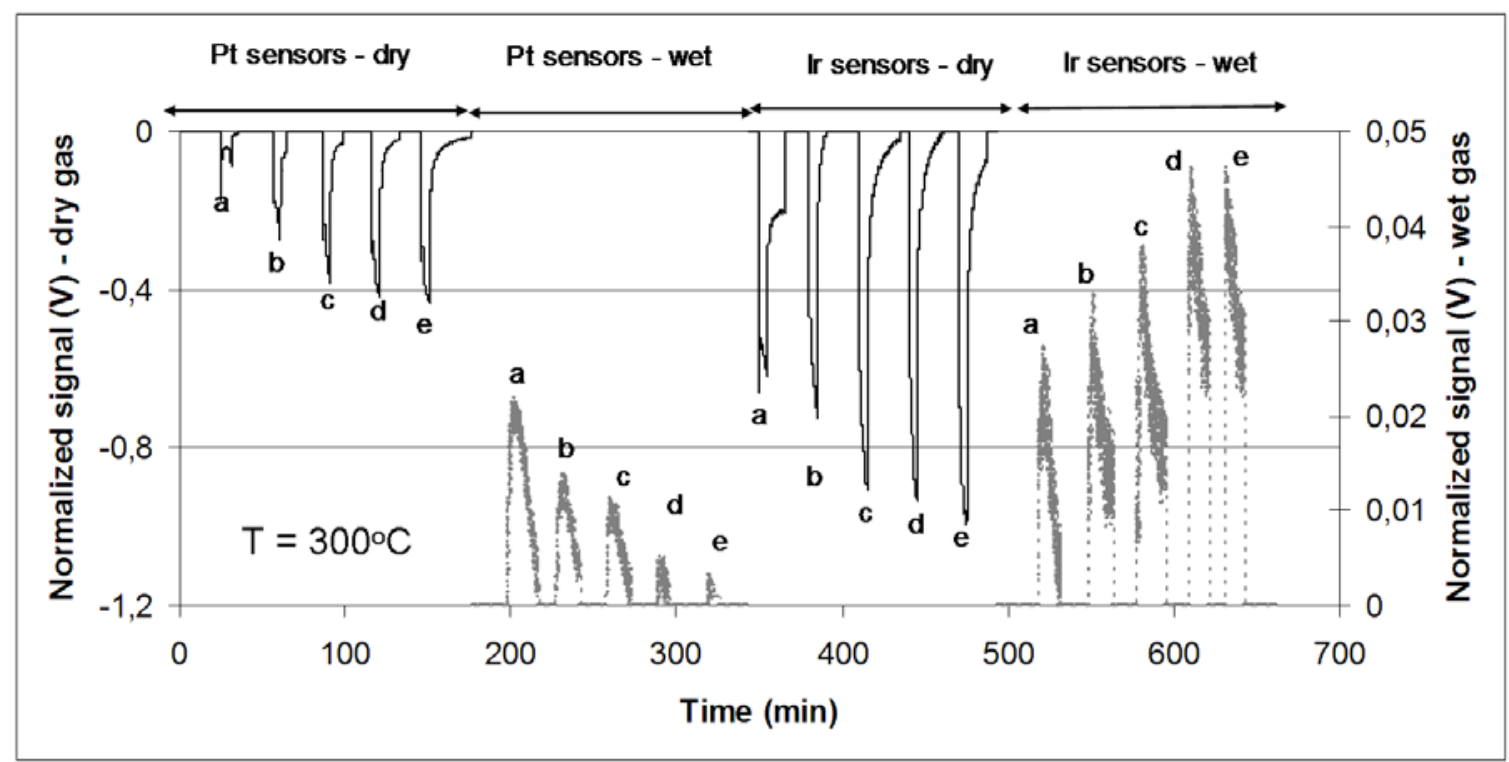

Methanol concentration (a) 200 ppm, (b) 400 ppm, (c) 800 ppm, (d) 1200 ppm, and (e) 1600 ppm Humidity level was kept constant at around $2 \%$

Figure 11 Influence of humidity for Pt and Ir sensors at $300^{\circ} \mathrm{C}$ 


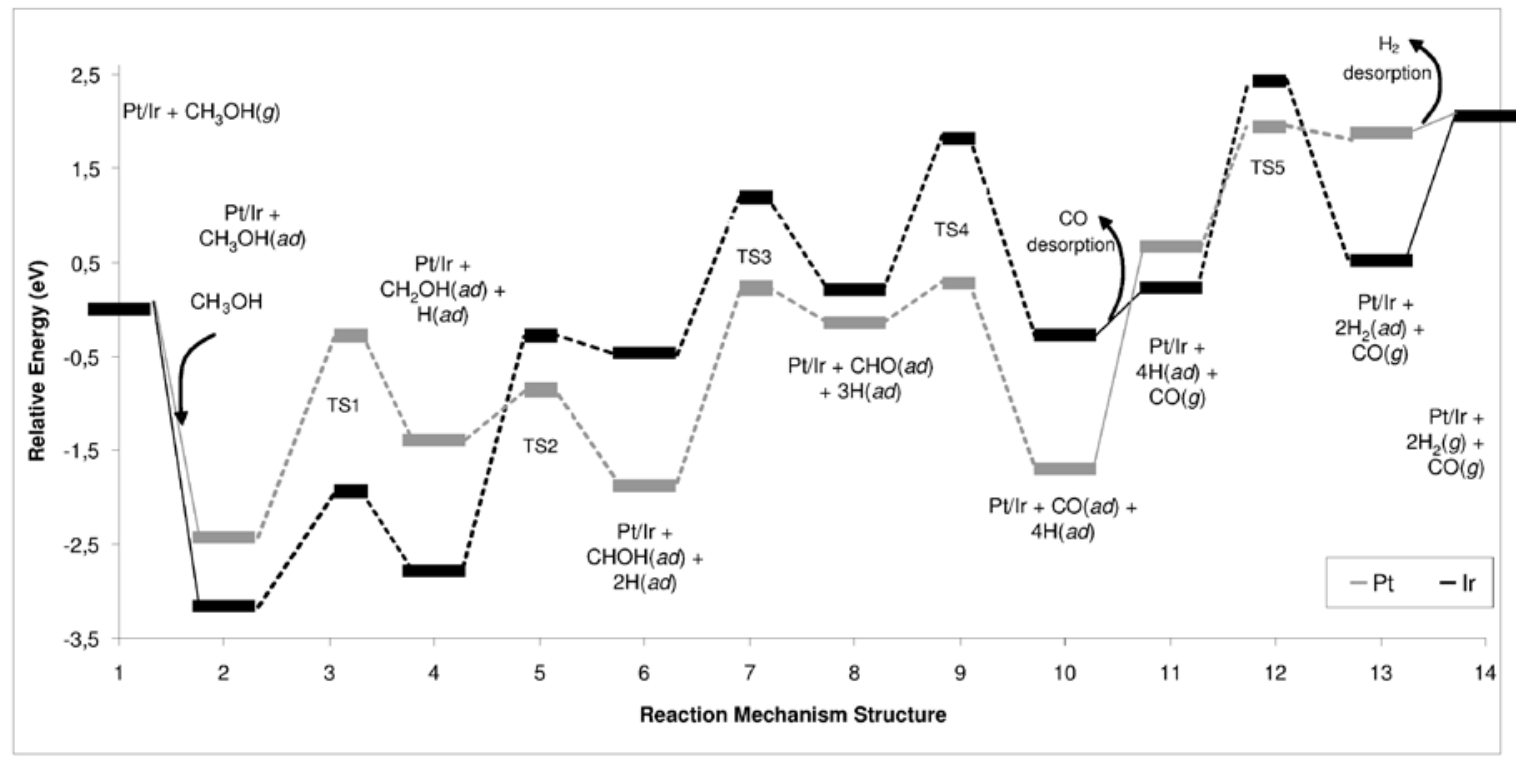

Figure 12 Potential energy profiles of methanol reactions on the sensor surface without oxygen. The reacting species are given in the Fig. 3. Quantum-chemical B3LYP/LanL2MB calculations 


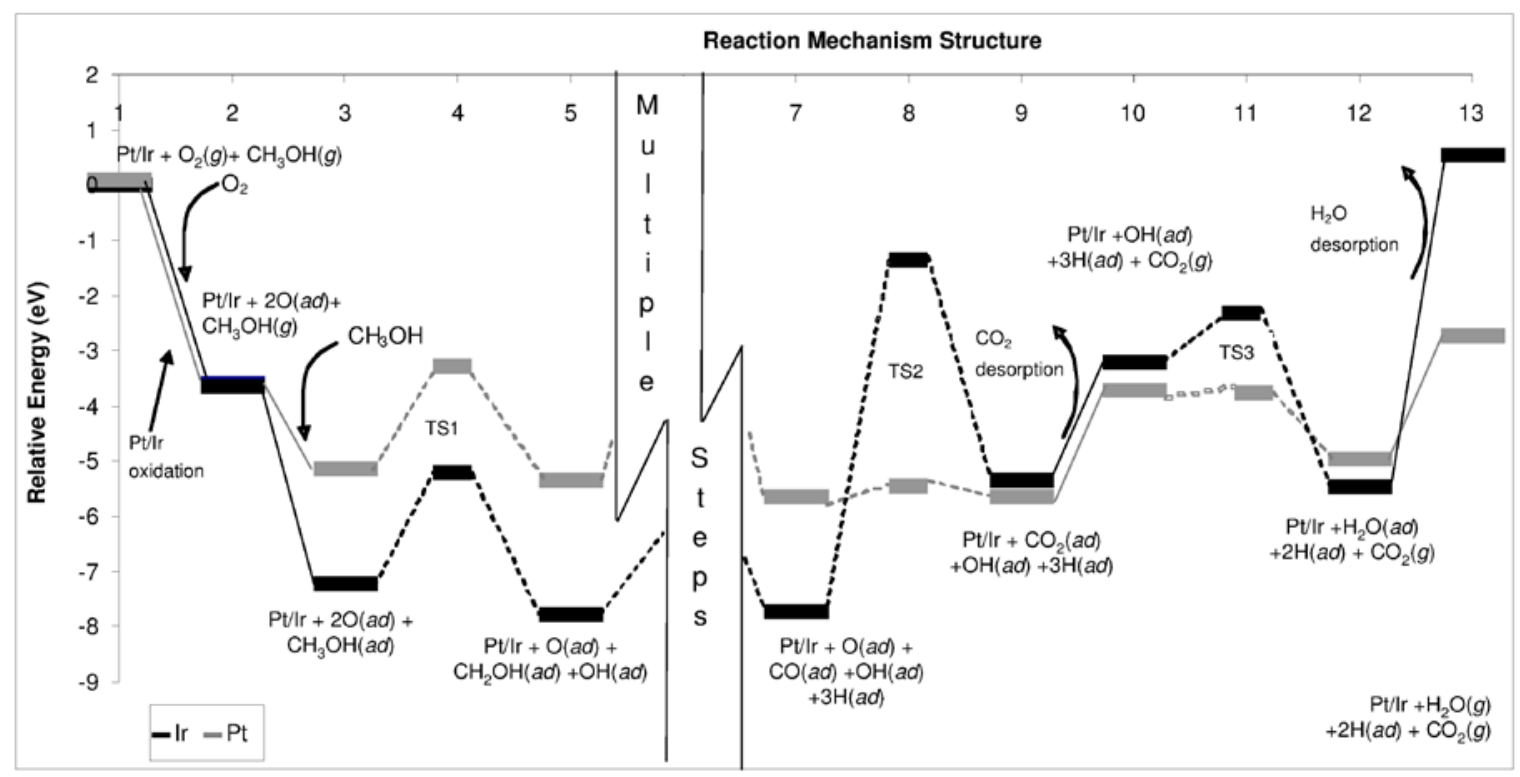

Figure 13 Potential energy profiles of methanol reactions on the sensor surface with the presence of oxygen 